\title{
A Brief Study on Sustainable Development of Interior Design and Decoration
}

\author{
Yaodong Li \\ College of Art and Information Engineering, Dalian Polytechnic University, 116100, China
}

Keywords: Interior design, Decoration, Sustainable development

\begin{abstract}
With the rapid development of the national economy, people place higher requirements on living standards and home environment, in which, the interior design plays a very important role. It becomes an important part in the construction industry currently. The decoration work is essential for interior design, which directly determines the show effect of interior design. In other words, there exists a certain connection or differences between decoration and interior design. Only if the designers and decorators work together, would create a comfortable and green living environment at reasonable prices, and meet the ecological needs of people on living space, which make a sustainable development on interior work.
\end{abstract}

\section{Introduction}

In recent years, our country has begun to build modern cities, which has made remarkable achievements. With the improvements of urban environment, the living environment also begins to change, especially the home indoor environment. The relevant staff needs to optimize designation appropriately after they have a detailed understanding of interior design and decoration ideas, which contain the introduction of personalized design, more emphasis on green design, the combination of ecological design ideas such as individual design, courtyard design and architectural design. Moreover, the relevant departments also need to enhance requirements on interior designers, to ensure the economic benefits of design and decoration businesses on the basis of creating a comfortable, green and simple indoor environment, and also lay a good foundation of sustainable development on interior design and decoration.

\section{The connection between interior design and decoration}

\section{The definition of interior design}

The interior design, which means to have a fair idea of architecture style, environment and the national standards, make a good combination of designers' knowledge of architectural aesthetics and some related technologies, design reasonable indoor environment which could satisfy people's material and spiritual needs.

Architectural interior design can reflect its value, as well as reveal various spiritual factors. During design stage, it requires designers to centre on customers and their life, and create a better living environment for them. Designers must faithfully implement their own work, determine the design style based on the following three factors: firstly, customers' use factor, which means to design on the basis of learning the use purpose and relevant wills. Secondly, indoor and surrounding environment, which means designers must have a fair idea of indoor and surrounding environment, to ensure effectiveness of the design. Thirdly, the customers' economic situation. Designers must learn customers' economic situation, and provide high-level design for higher income, inexpensive program for lower income. Only in this way can reflect the value of interior design, and increase the intensity of sustainable development.

Before designing, designers must put forward relevant requirements of the decoration and equipment, such as: materials, machinery, etc. During the process of designing, designers must master certain aesthetic principle, especially about construction, because interior design has strong artistry, it must abide by aesthetic principle. Meanwhile, designers also need to make regulation on design and decoration, price of decoration, and comprehensively consider the function, improve 
design quality on the basis of good indicative. Besides, designers need to know that the most important thing of architecture aesthetic is its practicability, interior design can be called successful only the interior environment with high practicability after the decoration.

\section{The difference between interior design and decoration}

Though both interior design and interior decoration are all for interior environment, but they still have many differences, which mainly manifested as the followings:

Firstly, interior decoration. Decoration means decoration on interior articles, it emphasize the interior appearance art and visual art. Decoration person must decorate the interior environment from multi-angles and decorate all the interior corners, such as: ground surface, walls, roof and so on. Decoration materials also can be furniture besides the painting materials.

Secondly, interior finishing. Interior finishing places emphasis on the combination of architectural engineering technology and construction technology. Its main work is to finish interior doors and windows after the accomplishment of the whole construction. The difference between interior decoration and interior finishing is that interior finishing emphasizes beautiful appearance as well as decoration quality to guarantee a good living environment for customers.

Thirdly, interior design. What interior design emphasizes is the interior visual environment and design technology. Its difference between interior decoration and interior finishing is that interior design has a strong integrity, which includes sounds, lamplight, sunlight, heat and other relevant design. It not only meets all kinds of physical demands of customers, but also meets their demand for psychology and artistic conception.

Though there are many differences among interior design, interior decoration and interior finishing, they all work for customers' living environment. Only relevant workers make full use of them to make good living environment for customers, can they give full play to their work advantages to establish a good foundation for the sustainable development of interior design, interior decoration and interior finishing.

\section{Sustainable development strategies for interior design, interior decoration and interior finishing}

\section{Establish new design concept}

Interior design has a special function, that is to provide people with good material life and spiritual life, among which, spiritual life occupies a very important position. In order to promote the sustainable development strategies for interior design, interior decoration and interior finishing, relevant workers need to establish the following design concepts:

Simple concept

Among numerous design concepts, simple concept is more fashionable. It can manifest the interior space decoration and finish in a simple way. However, at present, some decoration persons have not followed the simple design concept during the finishing process, for example, when design interior space for the rich, customers' demand for comfortable living environment is pretty high, relevant workers increase space according to the requirement, and the functions of these space should be different, during the process of increasing space, decoration persons can choose the entire wall partition, though space after decoration becomes much bigger in visual, but interior decoration cost also increase accordingly, design difficulty is relatively large, meanwhile it has negative influence on the adoption of sunlight. Therefore, relevant persons must abide by the simple concept, reasonably make use of color, ground surface, partition, lamplight and so on to express different functions of interior space, which can not only meet customers' demand, but also improve spatial comfort degree and reduce decoration time and cost to lay a foundation for the development of the enterprise.

Design concept of less is more

Design concept of less is more places emphasis on simple and functional design, it is against the attitude of over tedious decoration. This design concept have been popular for a very long time in western countries, it is still valued until now. Its main features are as followings: 
Firstly, emphasize rationalization. On the feature of rationalization, this concept mainly manifests on the furniture choose and interior arrangement. Traditional interior design makes multiple decorations to rooms, few people left space in the decoration process, which cannot create good living environment for customers. Therefore, relevant persons must abide by the rational decoration thought, to add funny factors and decrease material choose on the basis of clean and neat of the space, to make the space gain the effects of relax and peaceful, and to release people's work and life pressure.

Secondly, emphasize simplification. Simplification of interior decoration is to coordinate design furniture and interior environment, to improve elegance on the basis of simple space shape. For color design, choosing colors like black, white, gray, decreasing pattern decoration, thus can realize simplification as well as be connotation and generous. At the same time, when design the interior environment, designer should bold to using colors, like the collocation of neutral colors and main colors, should have a bright outline to express the effect of visual impact, thus can show the simple and pureness of the space as well as can outstand the fashion style.

Thirdly, contrast between materials and colors. In the simple design, the contrast between materials and colors is also emphasized, not only can be subtle but also exaggerate, for example, when redesign the walls, designers can combine white and milk color by using materials like brick and mirror, also can appropriately add bright colors to give prominence to the room color. During the coloring process, relevant persons should, firstly, ascertain main color of the space; then, ascertain color of furniture, pay attention to the demand of young people, when choose space, young people emphasize the individuality of the space decoration but not the size, especially the bedroom, not only to chase for individuality but also ask for refinement. Therefore, relevant persons should investigate on different kinds of people, summarize demands of different people on different spaces to optimize the space design concept and endeavor for the sustainable development of interior design, decoration and finishing.

\section{Abide by the greenization interior design principle}

Interior design can connect with material and spiritual civilization and better improve people's living environment. In recent years, people pay more attention to green ecology, positively purchase green food and drinks, also have corresponding requirements on their own living environment, therefore, present interior workers' most important task is to carry out greenization design, choose natural materials. Design objective is the harmonious development between people and ecology, they not only place emphasis on the design quality but also the application of science and technology to create ecological living environment for people on the basis of improving greenization design effects, to better guarantee human's health not being damaged by toxic material. Besides, interior designers also can refer to the advantages in the urban ecological design to make people live in the outside style space and promote the sustainable development of interior design, decoration and finishing.

\section{Enhance the fluidity of interior space}

When design interior space, designers must pay attention to the beauty and practicability of space as well as the fluidity. Firstly, interior decorative person can change the architecture to make it ventilated; secondly, relevant persons can decorate interior space according to the sunlight irradiation position to guarantee the better air ventilation. Thus can improve air quality as well as make the residential people enjoy a better scenery and improve their ideological level.

\section{Interior ecological design points}

In the process of interior ecological design, designers should clear design purpose, grasp design essentials to provide people with better living environment. If they want to guarantee the design quality, they must achieve the following points:

Firstly, designer can create ecological environment for publics through the courtyard design. For example, setting potting and flowers in the interior places can enhance residents' reaction to ecology. Meanwhile, relevant persons can help residents to bring in traditional potted landscape, thus can not only improve the ecological design quality of space but also benefit to the inheritance of national tradition culture. Besides, another method of courtyard design is to make interior garden, bring the 
courtyard design concept into interior space design, thus when people enjoyed the ecological living environment, they will give more supports to the interior design, decoration and finishing.

Decoration person can make use of freehand sketching to create landscape of mountain and water. For example, choosing soft colors to draw scenery, flowers, clouds and birds on the ball can enhance the ecological design effect as well as enhance art atmosphere for interior design.

Thirdly, large number of natural materials can be used in the process of interior ecological design, polishing processing for the original interior concrete ground surface, or simple finishing and decoration, keeping original lines on the basis of improving surface smoothness can make people feel local flavor, back to nature, and are benefit to reduce pressure of the urban people.

Fourthly, designers can design interior ecological sound and smell simulation system, such as voice of birds' singing and running water, flavor of flowers and trees, relevant persons need to gain knowledge of environmental ecology to meet residents' ecological requirements, and to increase science content on the basis of reasonably design living environment to make the ecological design work effectively.

\section{Respect residents' living habits}

Interior decoration is normally designed for living, in this process, designer should investigate the resident's hobby and living habits, choose reasonable design method according to the residents' daily life, to make space be more of living, thus residents will accept interior design, decoration and finishing smoothly, to improve the work efficiency of the enterprise.

\section{Conclusion:}

In recent years, interior design becomes more and more popular for people, mainly because that with the improvement of living standard, people's requirements on living environment also gradually improved. In order to guarantee the sustainable development of interior design, decoration and finishing, designers must strictly abide by relevant requests, positively to understand the main points and common points, differences among interior design, decoration and finishing to find out the work discipline, appropriately set up new design concept, bring in decoration equipment, strictly require the material type and quality, emphasize simplification, ecologicalizatin, rationalization, take effective measures to create comfortable living environment, guarantee the simple, beautiful, generous, connotation, ecological and pollution-free of space, to make the sustainable development of interior design, decoration and finishing and the better development of national architecture industry.

\section{References}

[1] Cheng lijun, Zhang Jinrong. Discussion on the Influence of Sustainable Design Concept on the Interior Design. Interior Architecture of China, 2014(2):124-127.

[2] Yan Junxia, Chenyan. Brief Discussion on the Vicissitude of Style of Modern Interior Design. Research on Urban Construction Theory, 2013(21).

[3] ]Zheng Guo, Interior Decoration and Environmental Protection. Urban Construction, 2012(18).

[4] Gan wei, Qiu Lan. Research on the Interactive Application of interior Design. Interior Architecture of China, 2014(6):128-131.

[5] Yang Jitao. Discussion on the Interior Design on the Basis of Greenization. Anhui Architecture, 2014,21(6):19-20. 